\title{
ARTÍCULOS
}

\section{LOS VÍNCULOS ENTRE LA SOCIEDAD NOVOHISPANA Y EL ARTE. COLECCIONISMO EN LA DÉCADA DE 1620.}

\author{
Ester Prieto Ustio \\ Universidad de Sevilla \\ esterprieto@hotmail.com
}

Resumen: La numerosísima documentación conservada en el Archivo General de Indias, permite ahondar profundamente en los vínculos entre Europa y América desde diversas perspectivas y ámbitos de estudio a lo largo de casi seis centurias. Nuestro interés radica en el análisis de las obras artísticas contenidas en una serie de registros e inventarios de personajes vinculados a la Real Audiencia de México en 1622, pudiendo obtener de este modo, una evidencia más de la existencia del coleccionismo de pinturas y esculturas en el entorno virreinal mexicano. A partir de esta información, podremos comprobar la tipología de las piezas artísticas más solicitadas por la sociedad novohispana, así como la procedencia de las mismas, poniendo de manifiesto de esta manera los sistemas comerciales como la Carrera de Indias, y subrayando la relevancia de los intercambios culturales entre los continentes europeo y americano en las primeras décadas del siglo XVII.

Palabras clave: Coleccionismo, Nueva España, siglo XVII, pintura, virreinal, Real Audiencia.

Tittle: THE LINKS BETWEEN THE MEXICAN SOCIETY AND ART. COLLECTING IN THE DECADE OF 1620.

Abstract: The numerous documentation preserved in the General Archive of the Indies allows delving the links between Europe and America from different perspectives and fields of study over almost six centuries. Our interest lies in the analysis of the artistic works contained in a series of inventories of people linked to the Royal Audience of Mexico in 1622, thus being able to obtain further evidence of the existence of the collecting of paintings and sculptures in the Mexican viceregal environment. From this information, we will be able to verify the typology of the artistic pieces most requested by the society of New Spain, as well as the origin of them, thus highlighting commercial systems such as the Carrera de Indias, and underlining the relevance of the Cultural exchanges between Europe and America in the first decades of the $17^{\text {th }}$ century.

Keywords: Collecting, New Spain, $17^{\text {th }}$ century, painting, viceregal, Royal Audience.

\section{Introducción}

Entre 1620 y 1622, años de tránsito entre el fin del reinado de Felipe III y el

Recibido: 06-02-2020

Aceptado: $15-02-2020$

Cómo citar este artículo: PRIETO USTIO, Ester. Los vínculos entre la sociedad novohispana y el arte. Coleccionismo en la década de 1620. Naveg@mérica. Revista electrónica editada por la Asociación Española de Americanistas [en línea]. 2020, n. 24. Disponible en: <http://revistas.um.es/navegamerica>. [Consulta: Fecha de consulta]. ISSN 1989-211X. 
ascenso al trono de Felipe IV, en aras de frenar ciertas prácticas corruptas, ejemplos de mal gobierno y de controlar al personal vinculado a la administración, se comenzaron a desarrollar mecanismos de poder en las audiencias peninsulares, tanto en las dependientes de la Corona castellana y las chancillerías, como en las audiencias aragonesas ${ }^{1}$.

Uno de estos mecanismos fue la realización de inventarios por parte de su nómina de empleados, en los que se tenían que indicar datos como el comienzo de su relación laboral con la entidad, los bienes muebles, inmuebles y objetos de valor que estaban en su posesión, su estado civil, descendencia...

Esta medida también fue extendida a las reales audiencias establecidas en Indias, siendo muy beneficiosa en el ámbito de la Nueva España, gracias a la aplicación de la misma por el marqués de Gelves que, en 1621, viajó hacia este territorio para desempeñar el flamante cargo de virrey.

A su llegada, Diego Carrillo de Mendoza y Pimentel, se encontró con un gobierno con tintes caóticos, una administración en casos envilecida y cierto grado de inseguridad en las calles. Sus intentos de erradicar el cohecho y las malas praxis lo enemistaron con buena parte de la sociedad, incluido el propio arzobispo de México, Juan Pérez de la Serna, quien acabaría favoreciendo con sus acciones el tumulto de 1624. Tras este suceso, en el cual se produjeron decenas de muertos y el incendio del palacio virreinal, el marqués resultó siendo destituido².

\title{
2. Breve estado de la cuestión
}

El 14 de enero de 1622, Felipe IV rubrica en el Pardo una sorprendente real cédula en la cual se daba orden de que todo el personal vinculado a la administración desde 1592, tenía que informar acerca de sus posesiones y patrimonio:

\begin{abstract}
"Que de aquí adelante todos los presidentes de mis Consejos y Chancillerías, virreyes, consejeros, sin exceptuar ninguno, gobernadores, regentes y asistentes, alcaldes de mi casa y corte, fiscales, mis secretarios con ejercicio, oidores, alcaldes de mis Chancillerías y Audiencias y todos los ministros de mi Consejo de Hacienda y cualesquier personas que tuvieren de dar cuenta de ella, antes de que se les entreguen los títulos de los dichos cargos y oficios, presenten, en los consejos donde se despacharen los tales títulos, descripción e inventario auténtico y jurado, hecho ante las justicias, de todos los bienes y haciendas que tuvieren al
\end{abstract}

\footnotetext{
1 Para el conocimiento de estas "malas prácticas", remitimos a ANDÚJAR CASTILLO, Francisco y PONCE LEIVA, Pilar. Debates sobre la corrupción en el mundo ibérico, siglos XVI-XVIII. Alicante: Biblioteca Virtual Miguel de Cervantes, 2018.

2 Para ampliar información sobre la figura del marqués de Gelves en la Nueva España y su gobierno, véase BALLONE, Angela. The 1624 Tumult of Mexico in Perspective (c. 1620-1650): Authority and Conflict Resolution in the Iberian Atlantic. Leiden: Brill, 2017; BÜSCHGES, Christian. ¿Absolutismo virreinal? La administración del marqués de Gelves revisada (Nueva España, 1621-1624). En: DUBET, Anne y RUIZ IBAÑEZ, José Javier (coords.). Las monarquías española y francesa (siglos XVI-XVIII): ¿dos modelos políticos? Madrid: Casa de Velázquez, 2010, pp. 31-44; y MARTínEZ VEGA, Elisabeth. El marqués de Gelves: un militar del siglo XVII novohispano. MILITARIA. Revista de Cultura Militar. 1990, n. 2, pp. 87-101.
} 
tiempo que me entraren a servir. $Y$ siempre que los tales ministros y demás personas arriba referidas fueren promovidos por merced mía a otros cargos y oficios hayan de renovar y renueven el dicho inventario de bienes y hacienda con el crecimiento y disminución que hubieren tenido en ella. Y lo mismo sea y se entienda con cualesquier oficiales, ministros de mi casa en cuyo poder entran cualesquier maravedíes de mi Real Hacienda"3.

Alonso Cabrera, en aquel momento consejero de Cámara, recoge en su Memorial de 1622 la razón de esta medida:

"[...] el fin principal con que V.Magd. ha mandado hacer estos inventarios es para saber que ministros han servido con codicia y cuales limpiamente, para castigar en la forma que mejor pareciere a los primeros y servirse V. Magd. con mas confianza de los otros"4.

Diez días después de la proclamación del decreto, el 24 de enero de $1622^{5}$, se publica el formulario -compuesto por catorce puntos- que tenían que seguir los ministros a la hora de confeccionar los requeridos inventarios, en el que se incluían directrices como:

"1. Que declaren todos los lugares, jurisdicciones, señoríos, bienes, raíces, casas, heredamientos y términos redondos que tuvieren con particular mención de cada uno y lo que rentan, y si son heredados, o comprados, o de merced [...].

4. Los patronazgos, capillas o capellanías y memorias que hubieren heredado o fundado y las rentas que les ovieren dado u aplicado y en que están situadas y otras preeminencias y derechos que tuvieren valor y estimación [...].

11. Las joyas, diamantes, perlas, piedras preciosas, declarando todas juntas su valor.

12. La plata blanca y dorada que tuvieren, declarando los marcos de cada género 0 ,

13. Las librerías, tapicerías, colgaduras, pinturas, estrados, camas y demás menaje de precio, declarando en particular las que son, y el valor dellos. Y en cuanto al demás menaje menudo del servicio de casa, se pondrá por junto, sin que sea necesario declarar por menudo cada cosa. $Y$ en todos estos géneros declaren las haciendas suyas y de sus mujeres" ${ }^{\text {. }}$

\footnotetext{
${ }^{3}$ Archivo Histórico Nacional (en adelante AHN), Consejos, legajo 9141, y Nueva Recopilación, libro segundo, título IV, Madrid, 1640 vol. I, p. 75; cit. en GONZÁLEZ FUERTES, Manuel Amador y NEGREDO DEL CERRO, Fernando. Mecanismos de control de la corrupción bajo Felipe IV: los inventarios de ministros (1622-1655). Una primera aproximación. Tiempos modernos: Revista Electrónica de Historia Moderna. 2017, vol. 8, n. 35, pp. 434-435.

${ }^{4}$ AHN, Consejos, legajo 1429, f. 130. Memorial de Alonso de Cabrera, 1622; cit. en PEÑA, José Felipe de la. Oligarquía y propiedad en Nueva España, 1550-1624. Ciudad de México: Fondo de Cultura Económica, 1983, pp. 13-17.

${ }^{5}$ ANDÚJAR CASTILLO, Francisco; FEROS CARRASCO, Antonio y PONCE LEIVA, Pilar. Corrupción y mecanismos de control en la Monarquía Hispánica. Una revisión crítica. Tiempos modernos: Revista Electrónica de Historia Moderna. 2017, vol. 8, n. 35, p. 297.

${ }^{6}$ PEÑA, José Felipe de la. Oligarquía y propiedad... Op. cit., pp. 21-22.
} 
Hasta el momento, se conocen vestigios documentales de esta práctica en el entorno de la Nueva España y la Nueva Granada, conservados en el Archivo General de Indias, así como en el ámbito de corte, ubicados éstos en el Archivo Histórico Nacional?.

\section{Inventarios de bienes de autoridades de Nueva España}

Gracias a la publicación de José F. de la Peña titulada Oligarquía y propiedad en Nueva España 1550-1624, tenemos constancia de la existencia de cinco legajos pertenecientes a la Real Audiencia de México, los cuales fueron compilados entre 1622 y 1623 bajo la denominación Inventarios de bienes de autoridades de Nueva España, en los que se recoge este mecanismo de poder procedente de la Península. El tratamiento que hace el autor de los testimonios contenidos en estos documentos del Archivo General de Indias, es para la conformación de un estado de la cuestión económico y social del virreinato novohispano en la década de 1620.

Desde el punto de vista de la Historia del Arte, esta amplia documentación ha sido trabajada por Alberto Baena Zapatero, quien ha señalado algunos ejemplos de la tipología de "muebles pintados" realizados en Michoacán, recogidos en los legajos 261 y 262 de esta serie de inventarios ${ }^{8}$.

Creemos que también pudo ser abordada por Pedro J. González en su tesis doctoral El coleccionismo pictórico de las élites de poder en Nueva España a principios del Siglo XVII, ya que la descripción de la mencionada tesis se asemeja a lo recogido en estos documentos, pero el trabajo de investigación que mencionamos en la actualidad no cuenta con la autorización pertinente para ser consultado, por lo que nos ha sido imposible poder acceder a su contenido, y comprobar si es cierta nuestra suposición.

La información reunida en estos inventarios, consta de una gran relevancia para comprender el gusto artístico de la sociedad novohispana de las primeras décadas del siglo XVII ${ }^{9}$, así como los modos de vida de los diversos personajes que formaban

7 GONZÁLEZ FUERTES, Manuel Amador y NEGREDO DEL CERRO, Fernando. Mecanismos de control... Op. cit., pp. 432-460.

8 BAENA ZAPATERO, Alberto. Apuntes sobre la elaboración de biombos en la Nueva España. Archivo Español de Arte. Abr./Jun. 2015, vol. 88, n. 350, p. 181.

9 Para más información sobre el coleccionismo novohispano de la primera mitad del siglo XVII, véase AGUILÓ ALONSO, María Paz. El coleccionismo americano de objetos procedentes de ultramar a través de los inventarios de los siglos XVI y XVII. En: VV.AA. Relaciones artísticas entre España y América. Madrid: Centro Superior de Investigaciones Científicas, 1990, pp. 107-149; ASHFIELD, William; OLLERO-LOBATO, Francisco y FERNÁNDEZ VALLE, María Ángeles. Arte y patrimonio en España y América. Montevideo: Universidad de la República; Consejo Superior de Investigaciones Científicas; Escuela de Estudios Hispanoamericanos; Universidad Pablo de Olavide, 2014; CURIEL MÉNDEZ, Gonzalo. Ajuares domésticos. Los rituales de lo cotidiano. En: RUBIAL, Antonio (ed.). La ciudad barroca. Ciudad de México: El Colegio de México; Fondo de Cultura Económica, pp. 81-108; DOBADO Rafael y CALDERÓN, Andrés. Pintura de los Reinos. Identidades compartidas en el mundo hispánico: miradas varias, siglos XVI-XIX. Ciudad de México: Fondo Cultural Banamex, 2012; HOLGUERA CABRERA, Antonio; PRIETO USTIO, Ester y URIONZO LOZANO María. Coleccionismo, mecenazgo y mercado artístico en España e Iberoamérica. Sevilla: SAV; Universidad de Sevilla, 2017; y REVENGA DOMínGUEZ, Paula (ed.). Arte Barroco y Vida Cotidiana en el Mundo Hispánico. Entre lo sacro y lo profano. Córdoba: Editorial de la Universidad de Córdoba, 2017 (entre otros). 
parte de la audiencia mexicana, aunque en el presente trabajo, por cuestiones de extensión, centraremos nuestro análisis en el rastreo de las pinturas y esculturas existentes en los registros.

Al igual que sucede en otros documentos realizados a lo largo de la Edad Moderna, como inventarios post-mortem, cartas de dotes, juicios de residencia etc., la alusión hacia las obras artísticas en ocasiones es muy escasa, mencionándose únicamente la existencia de quadros, lienços, piezas de bulto, ymagenes... sin especificar la cantidad, iconografía, el autor, procedencia o la valoración económica de las piezas. En otros casos, solo se indica alguno de estos campos -por ejemplo, un lienzo de Flandes, dos pinturas de santos...-, lo cual dificulta la investigación y condiciona que tengamos estimaciones parciales del total de las obras, las temáticas que representan o sus tipologías.

El legajo México, 260 es uno de los que conforma el ya mencionado conjunto Inventarios de bienes de ministros y oficiales reales. Ubicado dentro de la sección Audiencia de México del Archivo General de Indias, contiene 219 inventarios de personajes vinculados a esta administración, como gobernadores, alcaldes, alguaciles, escribanos... de los cuales vamos a analizar un total de veinte documentos en los que se recoge algún tipo de dato sobre pinturas y esculturas que se ubicaban en las residencias de los diversos sujetos.

\subsection{Gobernadores}

Comenzando con los personajes de mayor rango vinculados a la audiencia ${ }^{10}$ y los cabildos novohispanos, nos encontramos con el inventario del almirante Bernardino de Cevallos $^{11}$, gobernador de Nuevo México entre 1614 y $1618^{12}$, en el cual se registran "Doce retablos biejos", de los cuales desconocemos si estaban conformados por pinturas, esculturas o una combinación de ambas técnicas, sus materiales o iconografía, ya que esta es la única información que se aporta.

\subsection{Regidores}

Continuando con el rango en función de la composición de los cabildos

\footnotetext{
10 Para más información sobre las personas que conformaban la audiencia novohispana, véase JIMÉNEZ PELAYO, Águeda. Élites y poder: México y España: siglos XVI al XX. Guadalajara: Universidad de Guadalajara, 2003; RAMOS PÉREZ, Demetrio. La formación de las sociedades iberoamericanas (1568-1700). Madrid: Espasa Calpe, 1999; RUIZ RIVERA, Julián y SANZ TAPIA, Ángel. La venta de cargos y el ejercicio del poder en Indias. León: Universidad de León, 2007; SARABIA VIEJO, María Justina y PAZOS PAZOS, María Luisa. Orden y delincuencia. Los alguaciles de las ciudades novohispanas, siglos XVI-XVII. En: REY TRISTÁN, Eduardo y CALVO GUTIÉRREZ, Patricia. 200 años de Iberoamérica (1810-2010): Congreso Internacional: Actas del XIV Encuentro de Lationoamericanistas Españoles. Santiago de Compostela: Universidade de Santiago, 2010, pp. 684697; y VV.AA. Justicia, sociedad y economía en la América española siglos XVI, XVII, XVIII: trabajos del VI Congreso del Instituto Internacional de Historia del Derecho Indiano en homenaje al Dr. Alfonso García-Gallo. Valladolid: Casa-Museo Colón, 1983.

${ }^{11}$ Archivo General de Indias (en adelante AGI), México, 260, N. 54, f. 139v. Realizado en la Ciudad de México el 16 de julio de 1622.

12 Cfr. FULSOM, Harry. The Governors and Franciscans of New Mexico: 1598-1700. Indiana: iUniverse, 2014, pp. 10-23.
} 
americanos $^{13}$, en el caso de los regidores, aparecen elementos artísticos en los inventarios de tres varones que ostentaron este cargo.

Simón Enríquez ${ }^{14}$ fue un destacado funcionario del momento, y es que además de regidor de la Ciudad de México, también desempeñó los cargos de diputado fiel ejecutor, obrero mayor de propios y depositario general, todos vinculados a la capital novohispana. Para su desempeño, tuvo que demostrar su limpieza de sangre, debido a que era oriundo de Portugal, siendo este testimonio considerado como uno de los primeros documentos escritos en lengua portuguesa conservados en las actas del cabildo de esta ciudad ${ }^{15}$.

El 15 de julio de 1622 realizó el requerido documento de control, en el que declara que posee "dos pinturas de S[an] Antonio de Padua en lienco que valen veynte y cinco $\mathrm{p}[\mathrm{es}]^{\circ}[\mathrm{s}]$ [...], otras dos pinturas de la limpia conceoss ${ }^{\circ} \mathrm{n}$ [sic, Concepción] de n[ues]tra s[eñor $]^{\mathrm{a}}$ que valen quarenta $\mathrm{p}[\mathrm{es}]^{\mathrm{o}}[\mathrm{s}]$ " y "otra pintura del $s[a n] t^{\circ}$ franc[isc $]^{0}$ en tabla que vale diez $p[e s o s]^{16 "}$.

Diego Moreno de Monroy, regidor también del cabildo de la Ciudad de México desde 1621 hasta 1635 y heredero del mayorazgo que fundó su padre ${ }^{17}$, incluye entre sus posesiones:

"Un niño Jesus de oro guarnecido de jacintos q[ue] valdra cinquenta pesos.

Un santo domingo de oro con cinco diamantes pequeños y un rrubi q[ue] valdra cinquenta p[eso]s.

Una trinidad de oro guarnecida de diamantes que valdra trecientos pesos.

[...] Ocho quadros anusdeyes [sic, agnus dei] grandes y ocho laminas que valdran ciento y quarenta[...]"18.

Estos interesantes datos nos revelan la representación de personajes religiosos en el ámbito de la orfebrería, no solo en el pictórico o escultórico, aunando de esta manera lo decorativo y lo devocional, así como la presencia de ocho lienzos de igual temática, el Cordero de Dios.

13 Para una visión más amplia sobre el papel de los cabildos americanos, véase BERNABEU ALBERT, Salvador y VARELA BUENO, Consuelo. La ciudad americana: mitos, espacios y control social. Madrid: Ediciones Doce Calles, 2010; CAÑO ORTIGOSA, José Luis. Los Cabildos en Indias. Un estudio comparado. Corrientes: Moglia, 2009; GARCÍA BERNAL, Cristina; NAVARRO GARCÍA, Luis y RUIZ RIVERA, Julián. Élites urbanas en Hispanoamérica. De la conquista a la independencia. Sevilla: Universidad de Sevilla, 2005; y GARCíA BERNAL, Cristina. El municipio indiano. Relaciones interétnicas, económicas y sociales: homenaje a Luis Navarro García. Sevilla: Universidad de Sevilla, 2009.

14 CARRILLO, Fernando y CEPEDA, Fernando de. Relacion vniversal legitima, y verdadera del sitio en qve esta fvndada la muy noble, insigne, y muy leal Ciudad de Mexico, cabeça de las Provincias de toda la Nueva España. Imprenta de Francisco Salbago, 1637, p. 15.

15 ISRAEL, Jonathan. Empires and Entrepots: Dutch, the Spanish Monarchy and the Jews, 15851713. Londres: Bloomsbury, 1990, pp. 325-326.

${ }^{16} \mathrm{AGI}$, México, 260, N. 67, f. 172v. Inventario realizado en la Ciudad de México el 18 de julio de 1622.

${ }^{17} \mathrm{AGl}$, Indiferente, 450, L.A 7, f. 35r.-38v. Real Provisión en la que se da facultad a Luis Moreno para llevar a cabo el mayorazgo.

${ }^{18}$ AGI, México, 260, 128, f. 333r.-333v. 
Esta iconografía estuvo presente desde los primeros tiempos del cristianismo ${ }^{19}$, adquiriendo gran difusión en el arte medieval y en la pintura flamenca del siglo XV, experimentando mucha popularidad a lo largo del siglo XVII por su carácter íntimo, puesto que era frecuente que el Agnus Dei apareciera en soportes de mediano o pequeño tamaño como un manso animal que va a ser sacrificado, pero sin mostrar los síntomas dramáticos de este episodio, contrastando la blancura de su pelaje con un fondo negro sobre el que se recorta, características que se observan claramente en las numerosas pinturas que sobre este tema realizó Francisco de Zurbarán en torno a 1630 y 1640.

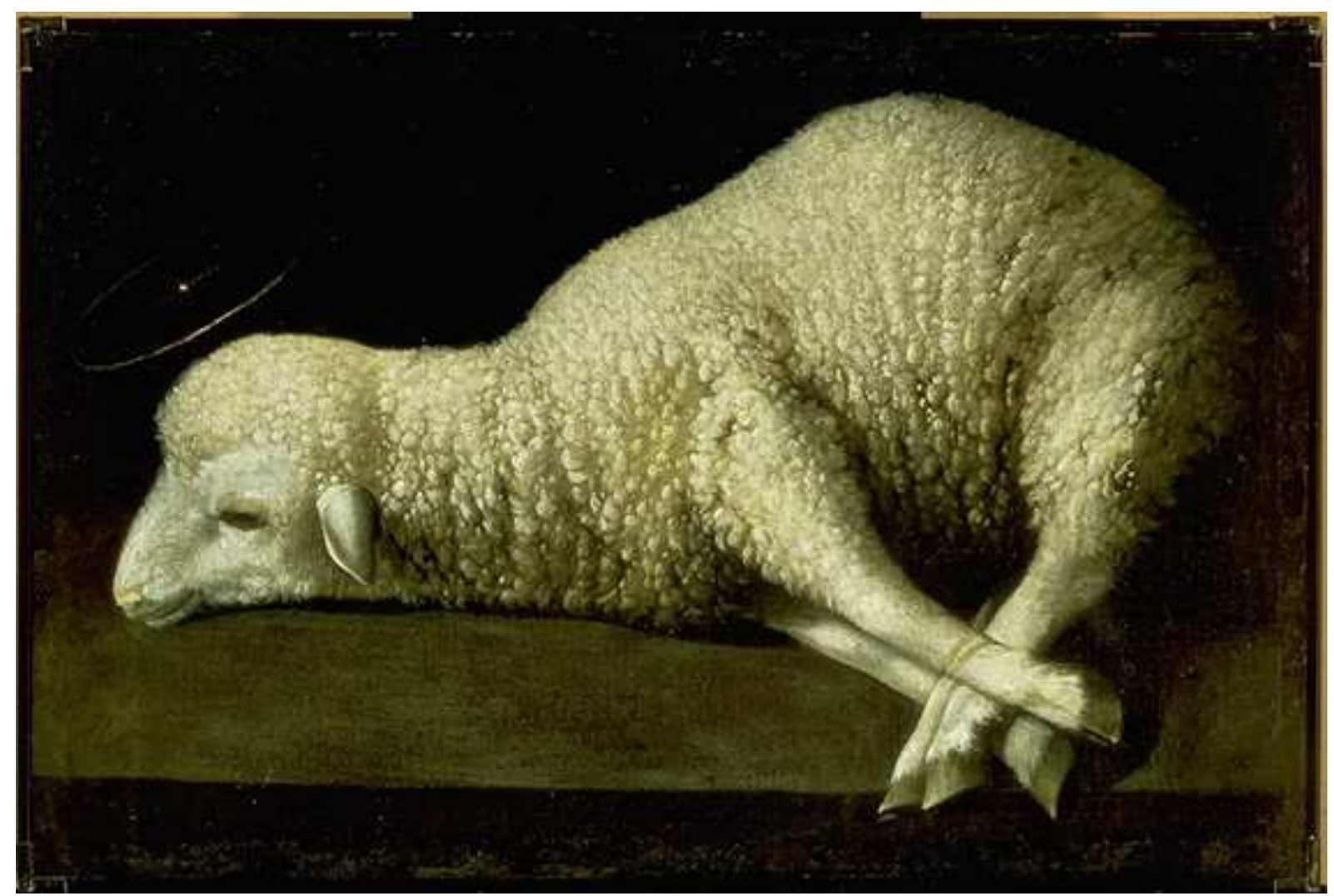

Fig. 1: Agnus Dei, Francisco de Zurbarán, c. 1635-1640. Fuente: The San Diego Museum of Art.

Otro ejemplo es el del regidor capitolino Juan Suárez de Figueroa, quien lleva a cabo el 23 de agosto de 1622 en Huauchinango su inventario de bienes ${ }^{20}$, registrándose:

"Un apostolado de med[i]a bara de alto en quince quadros que costaron cinco pesos cada uno montan setenta y cinco pesos de oro común.

Dose quadris con una beronica y de santo domingo de tres quartas de alto que costaron a siete pesos cada uno que montan ochenta y quatro pesos.

Quatro quadros de dos baras de alto uno de san cristobal otro de san niculas otro

${ }^{19}$ CARVAJAL GONZÁLEZ, Helena. El Agnus Dei. Revista digital de iconografía medieval. 2010, vol. 2, n. 4, pp. 1-7.

${ }_{20}$ AGI, México, 260, 193, f. 504r.-504v. 
de nolimitanger [sic, Noli me tangere] otro de nuestro s[eño]r y en los pies mundo demonio y carne que costaba dosciento[s] pesos de oro común.

Dos veronicas de una bara de alto que costaron quince pesos de oro común.

Un san niculas de Tolentino en lamina y el marco de ebano de una tercia de alto y que costo cinquenta pesos.

Una ymagen de nuestra Señora de la limpia consep.cion [sic, Concepción] de bulto el cuerpo en un retablo costo cinquenta pesos de oro común.

Una imagen de nuestra señora de la consepcion [sic, Concepción] de bulto de marfil de tres quartas de alto con corazón de plata dorada y esmaltada que costo ducientos pesos.

Beinte quadros de todas hechuras de santos de a quarta de media bara de tabla y en lienso y que costaron cien pesos de oro común".

Aunque no se mencionan las autorías, la información con la que se acompañan estas obras de arte es muy sugerente, pues se detalla el número exacto de unidades, el material con el que estaban ejecutadas, sus medidas, estimaciones económicas y temáticas representadas. Los datos nos permiten comprobar el gusto de Juan Suárez de Figueroa por el arte religioso, ya que en su inventario no se documenta ninguna pieza de carácter profano, destacando las representaciones de San Nicolás de Tolentino, la Verónica y la Inmaculada Concepción, iconografías de las que tenía más de un ejemplar.

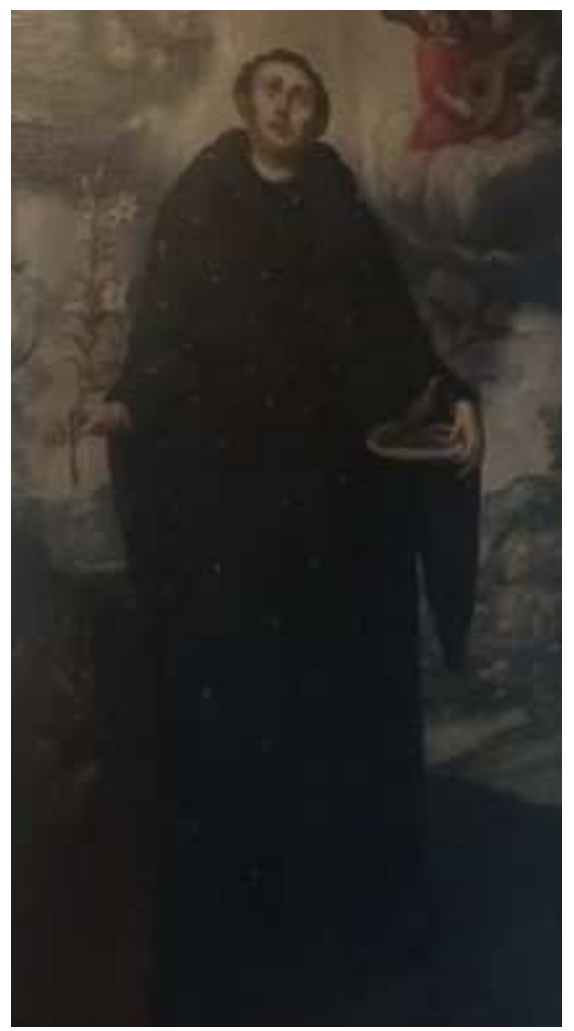

Fig. 2: San Nicolás de Tolentino. Anónimo novohispano, principios del siglo XVIII. Fuente: Museo de Arte Religioso Ex Convento de Santa Mónica (Imagen de la autora, 2019). 
El regidor tenía una inclinación diversa en cuanto los soportes de las obras. En el documento, se observan tanto lienzos como tablas, láminas, esculturas de madera y de marfil, sumando todo el conjunto cincuenta y siete piezas. Un reseñable número con el que podemos afirmar que, Suárez de Figueroa, fue uno de los miembros del organismo metropolitano en su tiempo con mayor cantidad de obras de arte en su domicilio, las cuales seguían las directrices iconográficas del momento desarrolladas en la Península, reforzadas para potenciar la devoción particular y adaptarse a las propuestas de la reforma tridentina.

\subsection{Corregidores y tenientes de corregidores}

Siguiendo el escalafón de los miembros de la Real Audiencia de México y cabildos, hallamos la figura del coleccionista entre algunos corregidores, aunque sus inventarios de bienes no son tan descriptivos como los de los anteriores personajes tratados.

Lorenzo Busto de Mendoza, corregidor de Huatlatlauca y Huehuetlán en el momento de llevar a cabo el requerimiento documental ordenado desde la Península, y más adelante alcalde de la Ciudad de México, señala que posee "veintiquatro lienzos dedi ferentes sanctos valen cinquenta y dos pesos"21.

Pocos datos a nivel artístico son los que aportan Juan Andrés Carrera, teniente de corregidor en Xochimilco: "seis en lienco muy biexos que baldran hasta treinta $\mathrm{p}[\mathrm{es}]^{0}[\mathrm{~s}]^{\prime 22}$, o su superior, don Pedro de Castilla Altamirano, corregidor de esa misma ciudad, quien desempeñó también los cargos de alcalde mayor en Chalco, Cuautitlán y Jilotepec, además de ser capitán de la guardia del virrey Luis de Velasco y Castilla, tenía en su ajuar: "un oratorio, pinturas y laminas y otras cosas pertenecientes baldran mil $\mathrm{p}[\mathrm{es}]^{0}[\mathrm{~s}]^{\prime 23}$.

La referencia en torno a la procedencia de la obra de arte revestía de interés a la misma y sumaba a la hora de valorarla económicamente, además de ser una prueba en el funcionamiento de los sistemas comerciales establecidos en la Edad Moderna entre los distintos continentes, como sucede con "la [h]echura de un Cristo de palo [h]echo en Castilla con su dosel de rraso negro bordado de oro y plata", que junto a "dies y nu[e]be rretablos de diferentes [h]echuras que balen sien pesos" 24 , que se documentan en el inventario de Jerónimo González Siciliano, corregidor de Maravatío, Huayacocotla e Ixcateopan y descendiente de los primeros conquistadores.

En relación con el origen de las piezas, fueron muy frecuentes las denominadas "pinturas o lienzos de Flandes"25, ejemplos plásticos ejecutados en la región

\footnotetext{
${ }^{21}$ AGI, México, 260, 33, f. 84r.

${ }^{22}$ AGI, México, 260, 43, f. 103v. Inventario realizado en Xochimilco el 4 de agosto de 1622.

${ }^{23} \mathrm{AGI}$, México, 260, 49, f. 124r. El inventario fue compuesto el 13 de julio de 1622 en la Ciudad de México.

${ }^{24}$ AGI, México, 260, 88, f. 232r.-233v.

${ }^{25}$ BLANCO, Mercedes. Lienzo de Flandes. Las soledades y el paisaje pictórico. En: GARCíA DE ENTERRÍA, María Cruz y CORDÓN MESA, Alicia (eds.). Actas del IV Congreso Internacional de la Asociación Internacional Siglo de Oro (AISO). Alcalá de Henares: Universidad de Alcalá, pp. 263-274.
} 
flamenca durante el Quinientos y en el Seiscientos ${ }^{26}$, los cuales tenían una alta estima en la Península en este tiempo, como puede comprobarse en los inventarios de personajes de diversos niveles socioeconómicos - desde las profesiones más humildes hasta los monarcas-, gusto que se trasladó hacia los virreinatos americanos.

Aunque tenían esta denominación genérica, las principales temáticas de estos ejemplos prácticos ejecutados en el norte de Europa eran los paisajes naturales y marítimos, vistas urbanas, ruinas, escenas navales, combates y batallas, -las cuales no fueron muy trabajadas por los pintores españoles de las primeras décadas del XVII-, sucesos de la mitología y escenas de género, principalmente.

\subsection{Alcaldes}

Los alcaldes, bien de los diferentes territorios del Virreinato, de la capital o de la Real Audiencia, contaron también con objetos artísticos en sus ajuares domésticos, aunque de modo similar al de los corregidores, la información relativa a este tipo de piezas es más bien escasa a excepción de dos personajes.

De Diego de Alarcón Maldonado, alcalde mayor de las Cuatro Villas del Marquesado de Oaxaca por merced y título del marqués del Valle, conocemos que entre sus bienes se encontraban "tres rretablos de pinturas grandes que baldran ciento y cinquenta pesos y seys laminas que baldran veynte pesos"27; similar a Antonio de Carvajal y Tapia, alcalde mayor de Tepeyac, quien también afirma poseer retablos: "[...] de libros y laminas tengo algunos Retablos balor de quinientos p[esos]"28; o a Manuel Francisco de Gauna, alcalde mayor de Xalatzingo, que declara: "tengo once quadros de ymagenes de diferentes pinturas", las cuales junto a tres escritorios y dos baúles, estaban valorados en trescientos cincuenta pesos ${ }^{29}$.

Las denominadas pinturas de imágenes pueden hacer alusión a representaciones hagiográficas, marianas o cristológicas, dentro del ámbito religioso, o bien a escenas mitológicas, como césares a caballo, hombres de honor, sibilas o emperadores, las temáticas profanas más populares en el tráfico colonial de la primera mitad del siglo XVII30.

\footnotetext{
${ }^{26}$ HUARD-BAUDRY, Emmanuelle. En torno a las Soledades: el abad de Rute y los lienzos de Flandes. Criticón. 2012, n. 114, pp.139-178.

${ }^{27}$ AGI, México, 260, 6, f. 15 r.

${ }^{28}$ AGI, México, 260, 42, f. 102 r.

${ }^{29}$ AGI, México, 260, 83, f. 219v.

30 PRIETO USTIO, Ester. Pinturas y pintores peninsulares en el ámbito de Nueva España durante la primera mitad del siglo XVII. En: GIMÉNEZ CHORNET, Vicent y VIADEL COLOMER, Antonio (eds.). I Congreso Internacional América-Europa, Europa-América. Valencia: Editorial Universitat Politécnica de Valencia, 2015, pp. 193-215.
} 


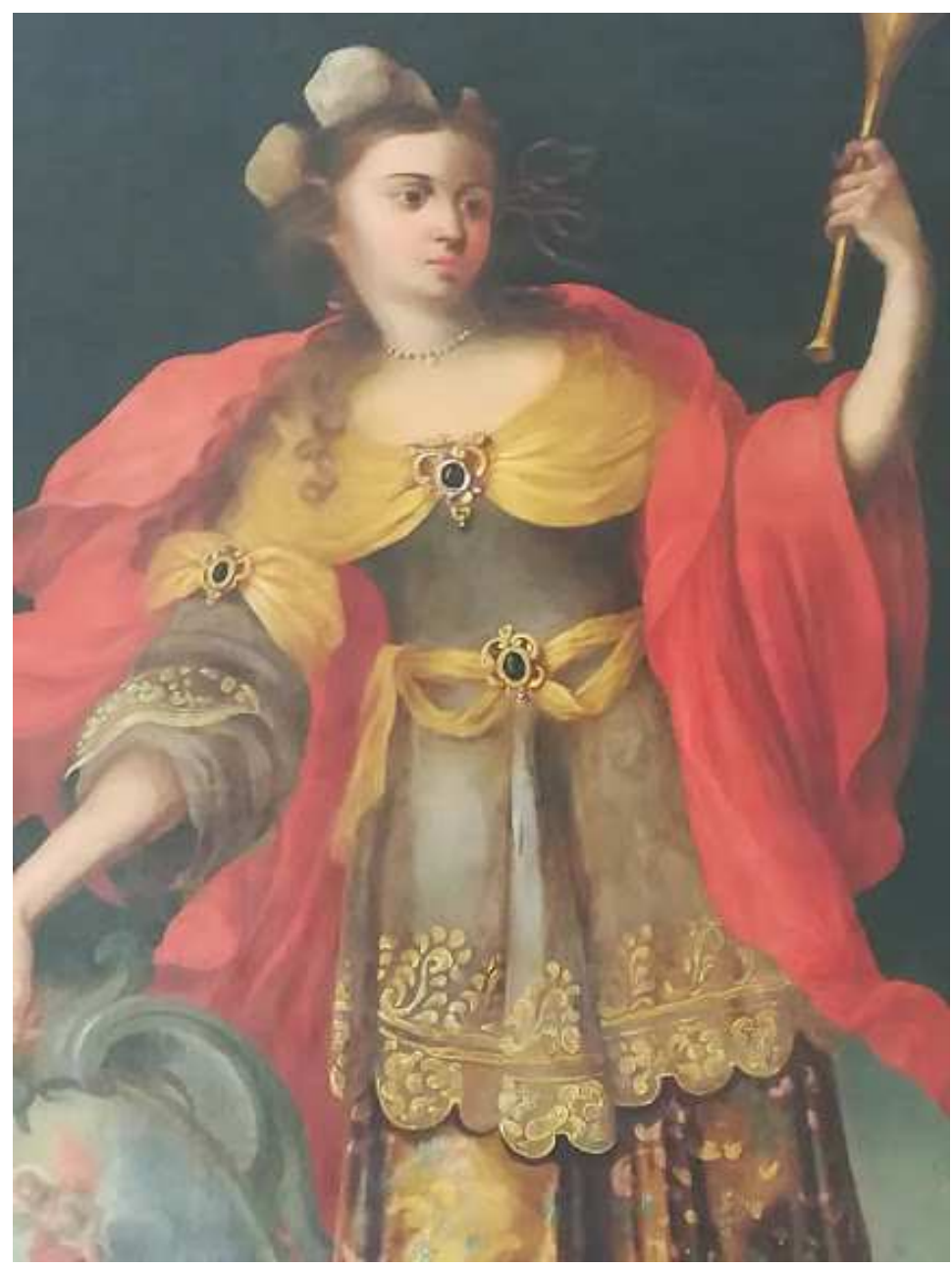

Fig. 3: Sibila Délfica (detalle). Anónimo novohispano, principios del siglo XVIII. Fuente: Museo Nacional de Historia de México (Imagen de la autora, 2019).

Al no especificarse la cantidad de obras es complejo poder hacer una comparativa entre sus precios, pero llama la atención los treinta pesos en los que estaban valoradas las piezas de Juan de Cabrera Arriaga -alcalde mayor de Teotlalco y descendiente de conquistadores-: "unas ymagines que las hechuras valdran hasta treinta $\mathrm{p}[\mathrm{e}] \mathrm{s}^{\circ}[\mathrm{s}]^{* 31}$, con los trescientos pesos de las pinturas de Fernando de Oñate y Rivadeneira -alcalde mayor de Texcoco y corregidor más delante de Totolapa-: "[...]de quadros y pinturas trescientos $\mathrm{p}[\mathrm{eso}] \mathrm{s}$ "32.

El bachiller Rodrigo de Zúñiga tuvo varios puestos en la gestión virreinal, siendo alcalde mayor de la Ciudad de México e Ixmiquilpan, además de corregidor capitolino, en Huejutla y Teozacoalco, y en su domicilio almacenó:

"Quatro quadros medianos el uno de la limpia concepción de n[uest]ra s[eñor] ${ }^{a}$ y otro de n[uest]ra s[eñor] ${ }^{a}$ y sant Joseph con El niño J[esú]s de la mano y el p[adre] Eterno y el [e]spiritu s[an]to y otro de El glorioso sant Nicolas de Tolentino y otro de santa Catherina Virgen y mártir todos al olio q[ue] valen quarenta $\mathrm{p}[\mathrm{es}]^{\circ} \mathrm{s}$ de oro"33.

\footnotetext{
${ }^{31}$ AGI, México, 260,36, f. 91r.

32 AGI, México, 260, 144, f. 371r. Documento firmado en la Ciudad de México el 14 de julio de 1622.

${ }^{33} \mathrm{AGI}$, México, 260, 219, f. 577r. Inventario compuesto el 19 de julio de 1622 en la Ciudad de México.
} 
Estas representaciones manifiestan las temáticas más solicitadas entre la sociedad peninsular del momento, como la Inmaculada Concepción -cuyo culto, y por ende, ejemplos artísticos, tuvieron un grandísimo desarrollo a lo largo del siglo XVII en los panoramas pictóricos, escultóricos y grabados- y las dos Trinidades iconografía que, generalmente, en el estadio terrenal se personificaba la Sagrada Familia, y en el celestial, el Padre Eterno junto a la paloma que simboliza el Espíritu Santo-, como se observa en pinturas y dibujos de Eugenio Cajés, Francisco Camilo, Bartolomé Esteban Murillo o Claudio Coello.

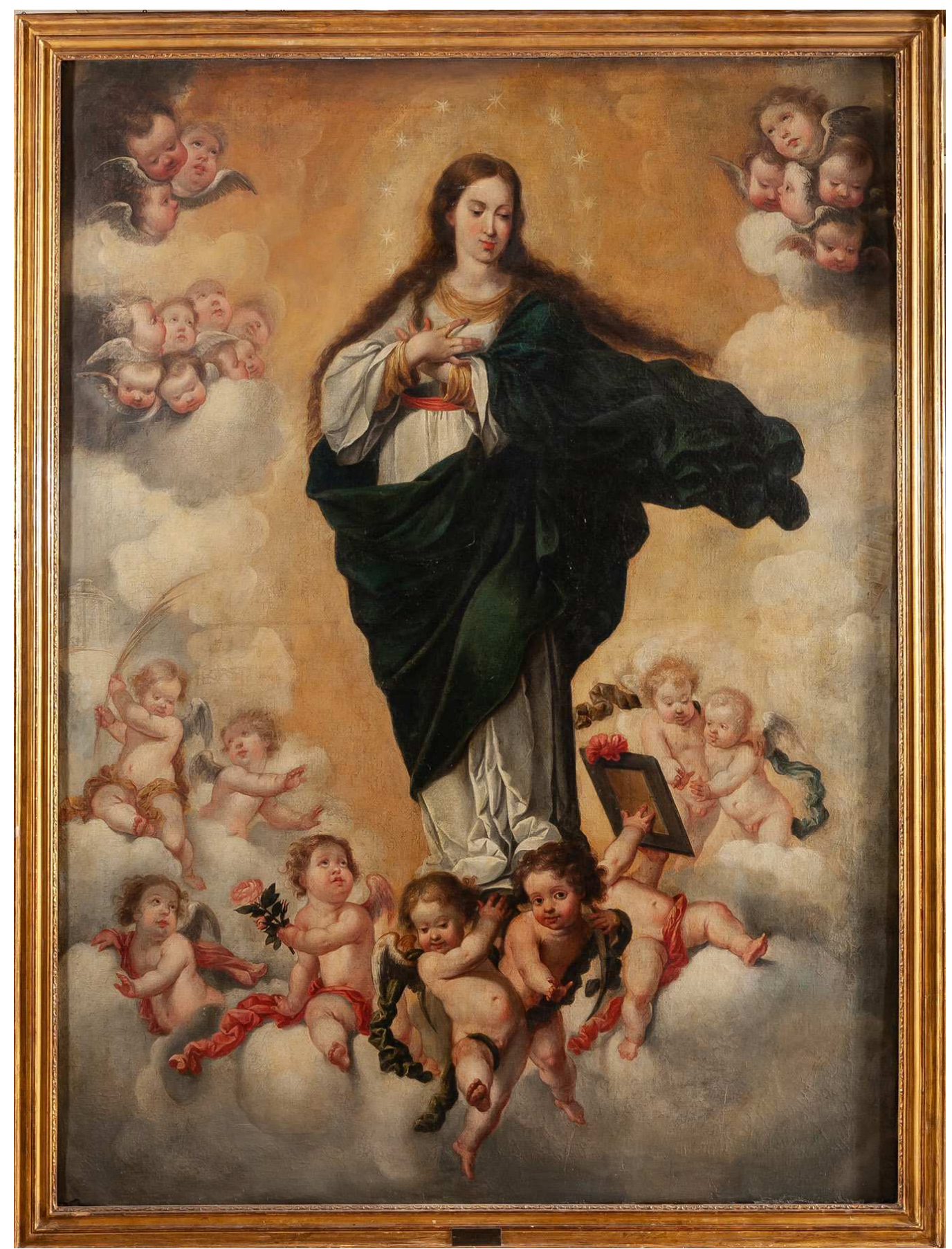

Fig. 4: Inmaculada Concepción. Escuela madrileña, ca 1620-1650. Fuente: Mercado del arte. 
También vemos ejemplos de iconografías muy demandadas en el ámbito novohispano, como San Nicolás de Tolentino -como ya comprobamos en el inventario de Juan Suárez de Figueroa- o Santa Catalina, ambos santos con gran veneración en América y patrones de numerosas localidades en el continente americano.

Dentro de la audiencia, el alcalde del crimen Miguel Ruiz de la Torre, que previamente había sido teniente de la villa de Madrid, alcalde mayor de Toledo y alcalde mayor de justicia de Sevilla y de quien ya comprobamos un aprecio por los objetos decorativos antes de su partida a la Nueva España, puesto que contó con una licencia de quinientos pesos para portar joyas en su viaje ${ }^{34}$, incluye en su inventario elementos como una completa biblioteca conformada por 153 títulos con un valor de mil ducados, colgaduras de Granada y:

"Trres laminas que son Santo Domingo y s[an]. Franc[isc]" y la madre Teressa guarnecidas de oro evano y cacar [sic, nácar].

Un niño Jhesus y S[an]. Juan con Un arquillo de oro en forma de coracon que todo esta apreciado en mil y seis r[ea]les.

Una tapicería De figuras Pequeñas de voscaxe [boscaje] entre fina Apreciada en quatro mil r[ea]les.

De Pinturas De devoción y otras en dos mil y quatrocientos Reales"35.

Destaca el alto valor económico que poseían sus piezas, lo cual en aquel momento, indicaba su calidad y buen estado de conservación, así como la aparición de objetos con doble funcionalidad, como las colgaduras y tapices, y la temática del "boscaje", la cual generalmente respondía a pinturas y textiles que representaban paisajes con un gran número de flora y fauna, muy habituales en los ambientes flamencos y holandeses.

\subsection{Alguaciles}

El primer inventario con registros artísticos entre alguaciles del virreinato novohispano en la década de 1620 es el de Esteban de Acosta Suárez ${ }^{36}$, alguacil mayor de las villas de San Miguel y San Felipe de los Chichimecas ${ }^{37}$-las actuales San Miguel de Allende y San Felipe Torres Mochas, en Guanajuato- en el que él mismo se denomina como "natural criollo de esta Nueva España".

De Acosta, declara, entre algunas de sus pertenecías, la vara de alguacil, una serie de casas y tiendas en San Miguel, y "menaje de casa con Alfombras coxines

\footnotetext{
${ }^{34} \mathrm{AGI}$, Indiferente, 450, L.A6, f.170v. Real Cédula que otorga la licencia mencionada.

${ }^{35} \mathrm{AGI}$, México, 260, 175, f. 448V-451r.

${ }^{36} \mathrm{AGI}$, México, 260, 2. Firmado el 15 de agosto de 1622.

37 En la Real Academia de la Historia se conserva un mapa de ambas villas con elementos antropomórficos de gran interés, realizado en torno a 1579-1580 y con signatura C-028-009. Cfr.: MANSO PORTO, Carmen. Los mapas de las Relaciones geográficas de Indias de la Real Academia de la Historia. Revista de Estudios Colombinos. 2012, n. 10, pp. 62-63.
} 
escriptorios quadros camas y todo el demas ajuar de Cassa", valorado en "mil y quinientos Pesos", sin indicar el número o más datos sobre esas pinturas, como ya hemos visto que sucede en otras ocasiones, misma coyuntura que con Diego Rodríguez de Trujillo, alguacil mayor de la propia Real Audiencia, que nos indica que sus obras son decorativas: "catorze rretablos que tengo para el adorno de la sala De mi c[a]sa q bibo balen ochenta $\mathrm{p}[\mathrm{es}]^{0} \mathrm{~s}^{\text {"38; }}$; o como uno de los alguaciles mayor de la Ciudad de México, Juan Rodríguez de Guevara, quien registra "dos docenas de quadros grandes de ymagenes de Pincel con sus guarniciones en trecientos pesos"39.

Dato sugerente es la inclusión de un lienzo de Santa Gertrudis en el inventario del alguacil de Xochimilco, Tomás de Monleón: "quatro liencos pequeñitos de n[uest]ra señora y uno de santa jertrudes y un cristo pequeño y estampas de papel que todo baldra diez pesos" 40 . La devoción a Santa Gertrudis fue muy popular en el entorno virreinal americano en los siglos XVII y XVIII, cuyo culto fue difundido por varias órdenes como los benedictinos, jesuitas o carmelitas. Aunque muchos autores han afirmado que esta religiosa fue nombrada patrona de las Indias Occidentales en 1609, esta referencia no ha podido ser probada documentalmente, aunque sí conocemos que el monasterio de la Concepción de México recibió ese mismo año el privilegio de poder celebrar la fiesta de la santa, siendo el segundo del mundo en obtenerlo $^{41}$. La representación iconográfica de la santa, generalmente se realizaba portando el hábito benedictino y el báculo de abadesa, acompañada del Sagrado Corazón de Jesús.

\footnotetext{
${ }^{38} \mathrm{AGI}$, México, 260, 170, f. 443r.

${ }^{39} \mathrm{AGI}$, México, 260, 167, f. 426v.

${ }^{40} \mathrm{AGI}$, México, 260, 122, f. 319r. Inventario compuesto en Xochimilco el 4 de agosto de 1622.

${ }^{41}$ RUBIAL GARCÍA, Antonio y BIEÑKO DE PERALTA, Doris. La más amada de Cristo. Iconografía y culto de santa Gertrudis la Magna en la Nueva España. Anales del Instituto de Investigaciones Estéticas. 2003, vol. XXV, n. 83, pp. 5-54.
} 


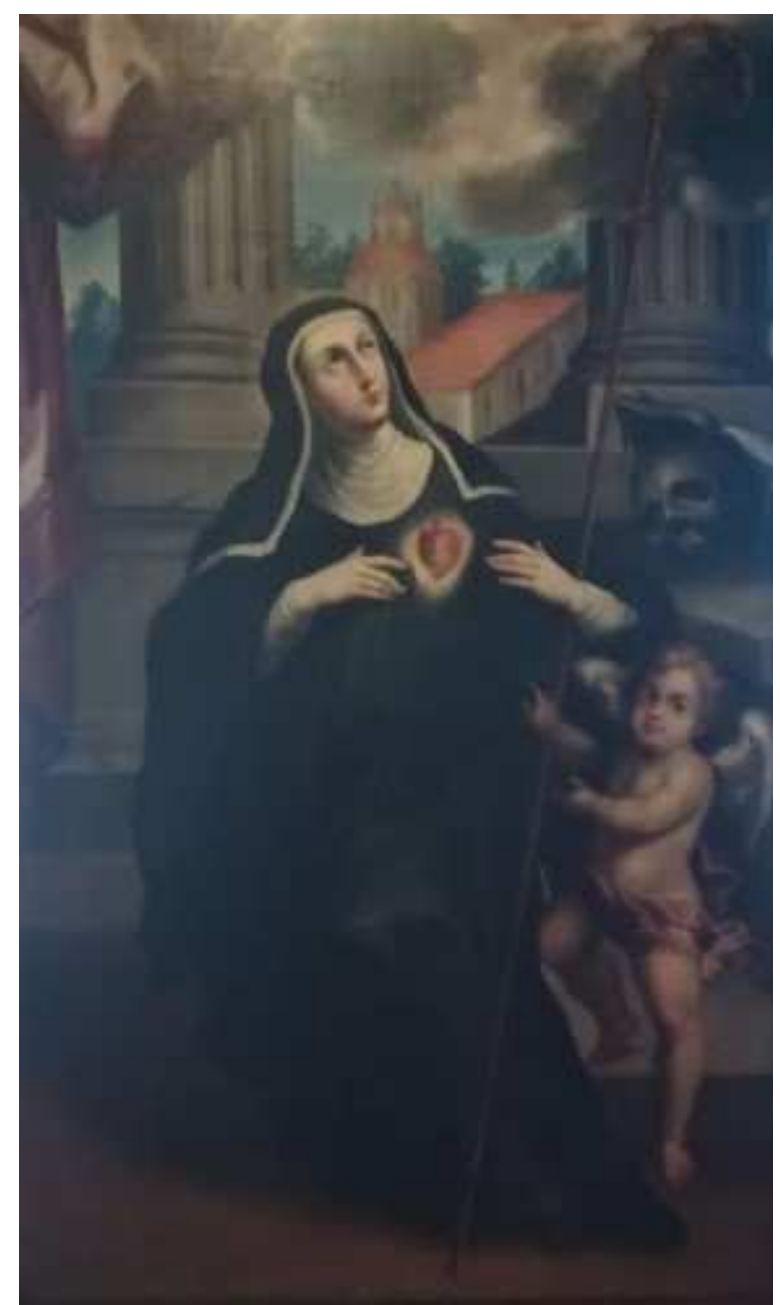

Figura 5. Santa Gertrudis. Anónimo novohispano, principios del siglo XVIII. Fuente: Museo de Arte Religioso Ex Convento de Santa Mónica (Imagen de la autora, 2019).

Variedad de objetos artísticos son los que nos encontramos en la documentación del bachiller Francisco García, alguacil mayor de Tlaxcala, quien además de una colgadura de tafetanes realizada en México, con un valor de trescientos pesos y una biblioteca con 130 volúmenes estimados en quinientos pesos, también poseía 44 pinturas -"catorze quadros del apostolado y treynta de diferentes santos balen docientos $\mathrm{p}[\mathrm{es}]^{\circ} \mathrm{s}$ "-, así como "tres laminas y un relicario balen docientos $\mathrm{p}[\mathrm{es}]^{\circ} \mathrm{s}$ " 42 .

La conformación del conjunto del Apostolado con catorce o quince piezas en vez de únicamente los doce seguidores señalados por Cristo, se debe a que, en ciertas ocasiones, se incluía en este tipo de serie las imágenes del propio Jesucristo, la Virgen y San Juan. Un ejemplo de la inclusión de estos tres personajes, puede observarse en el conjunto realizado por el pintor novohispano Juan Tinoco, conservado en la actualidad en su totalidad en la Museo Universitario de la Benemérita Universidad Autónoma de Puebla, sito en la Casa de los Muñecos de la capital poblana.

${ }^{42}$ AGI, México, 260, 80, f. 208v. 
A modo de interpretación de los datos presentados a lo largo de este texto, hemos realizado una serie de tablas incluidas en el anexo, en las que se recogen el número total de inventarios con los que hemos trabajado y el cargo administrativo de cada uno del personaje en cuestión, las iconografías que poseían las obras artísticas incluidas en cada uno de los inventarios -aquellas de las que tenemos datos, ya que como hemos comprobado, en algunos casos solo se mencionaba la tipología o soporte de la pieza, sin aportar más información sobre su temática o cantidad exacta de ejemplares- en las que destaca la total dedicación de las mismas a escenas religiosas.

En cuanto a la clasificación numérica de las piezas en relación a su tipología formal, nos ha resultado más complejo poder aportar datos concretos, y es que como observamos, en esta documentación lo más habitual era registrar las obras únicamente como "lienzos", "imágenes", "retablos", o "láminas", sin mayores especificaciones, pero los soportes y técnicas más populares en el momento fueron las pinturas, seguidas de los retablos y láminas.

\section{Conclusiones}

Para concluir este breve estudio, hemos constatado la importancia que tuvieron las medidas en contra de la mala praxis gubernamental y el cohecho. Las propuestas procedentes desde la Península, fueron correctamente acatadas por todos los funcionarios vinculados a la audiencia mexicana a lo largo de 1622.

Esta información, dada a conocer y tratada por investigadores como De la Peña, González Fuertes, Negredo del Cerro, Andújar Casillo, Ponce Leiva y Feros, ha sido interpretada desde los puntos de vista jurídicos, administrativos y económicos, pero al contener datos tan relevantes, permite nuevos acercamientos, como la vinculación a la historia del arte, y dentro de esta, al coleccionismo.

Tras el rastreo de los bienes artísticos contenidas en los veinte documentos con los que hemos trabajado, -correspondiéndose como ya hemos visto, un inventario perteneciente a un gobernador, tres de regidores, cuatro de corregidores, siete de alcaldes y cinco de alguaciles-, y sumando los datos numéricos posibles -en más de un caso no se indicaba el número total de obras-, nos da como resultado 247 piezas, siendo los ejemplos pictóricos los que más destacan, con 185 ejemplares -bien en lienzo o tabla-, seguidos de cuarenta y cinco retablos -los cuales podían estar conformados por esculturas o pinturas, o bien una combinación de ambas técnicas y soportes-, diez láminas -generalmente, pinturas sobre cobre u otro soporte metálico, tres esculturas de bulto, tres piezas de orfebrería -las hemos incluido ya que tenían una iconografía determinada y cierta concepción escultórica y una tapicería.

En cuanto a las representaciones de estas piezas, dentro de las que se pueden contabilizar, no hemos encontrado ningún ejemplo -que se mencione- de temáticas profanas, por lo que dentro de las materias religiosas, sobresalen cuarenta y cuatro imágenes de santos -englobadas aquí las que se mencionan únicamente con este nombre en los documentos-, seguidas de veintiséis pinturas que conforman Apostolados, ocho modelos del Agnus Dei, cinco ejemplos de la Inmaculada 
Concepción, cuatro piezas de la Virgen -sin especificar su advocación-, tres obras de San Francisco y otras tres de San Nicolás de Tolentino, dos imágenes de Jesucristo, dos de la Verónica y otras dos del Niño Jesús, así como una representación del Noli me tangere, otra de la Sagrada Familia, una Trinidad, un San Cristóbal, una Santa Catalina y una Santa Gertrudis.

Por el número de obras, podemos destacar como coleccionistas a Juan Suárez de Figueroa, quien poseía cincuenta y siete piezas, a Francisco García, el cual atesoró cuarenta y cuatro, a Lorenzo Busto de Mendoza, con veinticuatro pinturas, a Jerónimo González, sumando veinte ejemplares y a Diego Rodríguez con catorce. El resto de personajes analizados, registraron en los inventarios un total de obras que oscilan entre once y tres en función del sujeto.

Dichos datos son una evidencia que prueba la existencia de la práctica del coleccionismo en buena parte del virreinato novohispano, no solo por virreyes y nobles como se conoce gracias a otras investigaciones, sino también por personajes relacionados con el entorno de la administración de este territorio.

Gracias a estos sujetos que conformaban la sociedad procedente o radicada en la Nueva España de la segunda década del siglo XVII, podemos afirmar que, en el gusto estético y en los hábitos visuales del momento, primaba la práctica de la devoción particular, sobresaliendo las representaciones de santos, la Virgen y el Cordero de Dios, y siendo la pintura, la técnica predilecta para su plasmación.

Cabe señalar también que la mención a la procedencia de alguna de las obras, como los lienzos de Flandes o esculturas de Castilla, nos pone de manifiesto la productividad de la Carrera de Indias, y denota la llegada de estas piezas a suelo novohispano a través del comercio transatlántico.

\section{Bibliografía}

AGUILÓ ALONSO, María Paz. El coleccionismo americano de objetos procedentes de ultramar a través de los inventarios de los siglos XVI y XVII. En: VV.AA. Relaciones artísticas entre España y América. Madrid: Centro Superior de Investigaciones Científicas, 1990, pp. 107-149.

ANDÚJAR CASTILLO, Francisco y PONCE LEIVA, Pilar. Debates sobre la corrupción en el mundo ibérico, siglos XVI-XVIII. Alicante: Biblioteca Virtual Miguel de Cervantes, 2018.

ANDÚJAR CASTILLO, Francisco; FEROS CARRASCO, Antonio y PONCE LEIVA, Pilar. Corrupción y mecanismos de control en la Monarquía Hispánica. Una revisión crítica. Tiempos modernos: Revista Electrónica de Historia Moderna. 2017, vol. 8, n. 35, pp. 284-311.

ASHFIELD, William; OLLERO-LOBATO, Francisco y FERNÁNDEZ VALLE, María Ángeles. Arte y patrimonio en España y América. Montevideo: Universidad de la República; Consejo Superior de Investigaciones Científicas; Escuela de Estudios 
Hispanoamericanos; Universidad Pablo de Olavide, 2014.

BALLONE, Angela. The 1624 Tumult of Mexico in Perspective (c. 1620-1650): Authority and Conflict Resolution in the Iberian Atlantic. Leiden: Brill, 2017.

BAENA ZAPATERO, Alberto. Apuntes sobre la elaboración de biombos en la Nueva España. Archivo Español de Arte. Abr./Jun. 2015, vol. 88, n. 350, pp. 173-188.

BERNABEU ALBERT, Salvador y VARELA BUENO, Consuelo. La ciudad americana: mitos, espacios y control social. Madrid: Ediciones Doce Calles, 2010.

BLANCO, Mercedes. Lienzo de Flandes. Las soledades y el paisaje pictórico. En: GARCÍA DE ENTERRÍA, María Cruz y CORDÓN MESA, Alicia (eds.). Actas del IV Congreso Internacional de la Asociación Internacional Siglo de Oro (AISO). Alcalá de Henares: Universidad de Alcalá, pp. 263-274.

BÜSCHGES, Christian. ¿Absolutismo virreinal? La administración del marqués de Gelves revisada (Nueva España, 1621-1624). En: DUBET, Anne y RUIZ IBAÑEZ, José Javier (coords.). Las monarquías española y francesa (siglos XVIXVIII): ¿dos modelos políticos? Madrid: Casa de Velázquez, 2010, pp. 31-44.

CAÑO ORTIGOSA, José Luis. Los Cabildos en Indias. Un estudio comparado. Corrientes: Moglia, 2009.

CARRILLO, Fernando y CEPEDA, Fernando de. Relacion vniversal legitima, y verdadera del sitio en qve esta fvndada la muy noble, insigne, y muy leal Ciudad de Mexico, cabeça de las Provincias de toda la Nueva España. Imprenta de Francisco Salbago, 1637.

CARVAJAL GONZÁLEZ, Helena. El Agnus Dei. Revista digital de iconografía medieval. 2010, vol. 2, n. 4, pp. 1-7.

CURIEL MÉNDEZ, Gonzalo. Ajuares domésticos. Los rituales de lo cotidiano. En: RUBIAL, Antonio (ed.). La ciudad barroca. Ciudad de México: El Colegio de México; Fondo de Cultura Económica, pp. 81-108.

DOBADO Rafael y CALDERÓN, Andrés. Pintura de los Reinos. Identidades compartidas en el mundo hispánico: miradas varias, siglos XVI-XIX. Ciudad de México: Fondo Cultural Banamex, 2012.

FULSOM, Harry. The Governors and Franciscans of New Mexico: 1598-1700. Indiana: iUniverse, 2014.

GARCÍA BERNAL, Cristina; NAVARRO GARCíA, Luis y RUIZ RIVERA, Julián. Élites urbanas en Hispanoamérica. De la conquista a la independencia. Sevilla: Universidad de Sevilla, 2005.

GARCÍA BERNAL, Cristina. El municipio indiano. Relaciones interétnicas, 
económicas y sociales: homenaje a Luis Navarro García. Sevilla: Universidad de Sevilla, 2009.

GONZÁLEZ FUERTES, Manuel Amador y NEGREDO DEL CERRO, Fernando. Mecanismos de control de la corrupción bajo Felipe IV: los inventarios de ministros (1622-1655). Una primera aproximación. Tiempos modernos: Revista Electrónica de Historia Moderna. 2017, vol. 8, n. 35, pp. 432-460.

HOLGUERA CABRERA, Antonio; PRIETO USTIO, Ester y URIONZO LOZANO María. Coleccionismo, mecenazgo y mercado artístico en España e Iberoamérica. Sevilla: SAV; Universidad de Sevilla, 2017.

HUARD-BAUDRY, Emmanuelle. En torno a las Soledades: el abad de Rute y los lienzos de Flandes. Criticón. 2012, n. 114, pp.139-178.

ISRAEL, Jonathan. Empires and Entrepots: Dutch, the Spanish Monarchy and the Jews, 1585-1713. Londres: Bloomsbury, 1990.

JIMÉNEZ PELAYO, Águeda. Élites y poder: México y España: siglos XVI al XX. Guadalajara: Universidad de Guadalajara, 2003.

MANSO PORTO, Carmen. Los mapas de las Relaciones geográficas de Indias de la Real Academia de la Historia. Revista de Estudios Colombinos. 2012, n. 10, pp. 62-63.

MARTÍNEZ VEGA, Elisabeth. El marqués de Gelves: un militar del siglo XVII novohispano. MILITARIA. Revista de Cultura Militar. 1990, n. 2, pp. 87-101.

PEÑA, José Felipe de la. Oligarquía y propiedad en Nueva España, 1550-1624. Ciudad de México: Fondo de Cultura Económica, 1983.

PRIETO USTIO, Ester. Pinturas y pintores peninsulares en el ámbito de Nueva España durante la primera mitad del siglo XVII. En: GIMÉNEZ CHORNET, Vicent y VIADEL COLOMER, Antonio (eds.). I Congreso Internacional América-Europa, Europa-América. Valencia: Editorial Universitat Politécnica de Valencia, 2015, pp. 193-215.

RAMOS PÉREZ, Demetrio. La formación de las sociedades iberoamericanas (15681700). Madrid: Espasa Calpe, 1999.

REVENGA DOMínGUEZ, Paula (ed.). Arte Barroco y Vida Cotidiana en el Mundo Hispánico. Entre lo sacro y lo profano. Córdoba: Editorial de la Universidad de Córdoba, 2017.

RUBIAL GARCÍA, Antonio y BIEÑKO DE PERALTA, Doris. La más amada de Cristo. Iconografía y culto de santa Gertrudis la Magna en la Nueva España. Anales del Instituto de Investigaciones Estéticas. 2003, vol. XXV, n. 83, pp. 5-54. 
RUIZ RIVERA, Julián y SANZ TAPIA, Ángel. La venta de cargos y el ejercicio del poder en Indias. León: Universidad de León, 2007.

SARABIA VIEJO, María Justina y PAZOS PAZOS, María Luisa. Orden y delincuencia. Los alguaciles de las ciudades novohispanas, siglos XVI-XVII. En: REY TRISTÁN, Eduardo y CALVO GUTIÉRREZ, Patricia. 200 años de Iberoamérica (1810-2010): Congreso Internacional: Actas del XIV Encuentro de Lationoamericanistas Españoles. Santiago de Compostela: Universidade de Santiago, 2010, pp. 684-697.

VV.AA. Justicia, sociedad y economía en la América española siglos XVI, XVII, XVIII: trabajos del VI Congreso del Instituto Internacional de Historia del Derecho Indiano en homenaje al Dr. Alfonso García-Gallo. Valladolid: Casa-Museo Colón, 1983.

\section{Anexo}

\begin{tabular}{|l|c|}
\hline \multicolumn{2}{|l|}{ № de inventarios } \\
\hline Gobernador & 1 \\
\hline Regidor & 3 \\
\hline Corregidor & 4 \\
\hline Alcalde & 7 \\
\hline Alguacil & 5 \\
\hline
\end{tabular}

Tabla 1. Tabla con el número de inventarios que recogen obras artísticas en función del cargo del personaje. Fuente: Elaboración propia.

\begin{tabular}{|l|c|}
\hline \multicolumn{2}{|c|}{ Iconografías de las obras de arte } \\
\hline Agnus Dei & 8 \\
\hline Apostolado (serie de 12 ó 14 lienzo) & 26 \\
\hline Inmaculada Concepción & 5 \\
\hline Jesucristo & 2 \\
\hline La Verónica & 2 \\
\hline Niño Jesús & 2 \\
\hline Noli me tangere & 1 \\
\hline Sagrada Familia & 1 \\
\hline San Antonio & 2 \\
\hline San Cristóbal & 1 \\
\hline San Francisco & 3 \\
\hline San Nicolás de Tolentino & 3 \\
\hline Santa Catalina & 1 \\
\hline Santa Gertrudis & 1 \\
\hline Santo Domingo & 14 \\
\hline Santos (en general, sin incluir más datos) & 44 \\
\hline Trinidad & 1 \\
\hline Virgen (sin especificar advocación) & 4 \\
\hline
\end{tabular}

Tabla 2. Tabla con las iconografías de las obras de arte y -ejemplares de cada una- especificadas en los inventarios (que se pueden contabilizar). Fuente: Elaboración propia. 


\begin{tabular}{|l|c|}
\hline \multicolumn{2}{|c|}{ Soportes } \\
\hline Lienzos, cuadros o pinturas & 185 \\
\hline Retablos & 45 \\
\hline Esculturas & 3 \\
\hline Artes decorativas & 3 \\
\hline Láminas & 10 \\
\hline Tapicerías & 1 \\
\hline
\end{tabular}

Tabla 3. Tabla con los soportes -y ejemplares de cada tipo- mencionados en los inventarios de bienes (que se puedan contabilizar). Fuente: Elaboración propia. 